\title{
FOLIE A DEUX.
}

BY D. HACK TUKE, M.D., F.R.C.P.

Cases of Folie à deux, for which we have not a good corresponding English term, are sufficiently uncommon to warrant my recording some interesting examples, and making them the occasion for a few observations. "Communicated Insanity" is the best term $I$ know of, but it does not cover those cases in which the disorder is not strictly speaking communicated, and which the French include. "Double Insanity" is one synonym, but then it must be understood that I include under this head cases in which a greater number of persons become affected.

It is important to understand clearly what we mean by the phrase Folic à deux. Is the element of contagion, in the sense that fear is contagious, an essential part of the definition, or is it sufficient that two or more persons become mentally affected at the same time, and when together, by means of the same exciting cause? Or, again, may we stretch the definition to include the insanity of twins when they become insane contemporaneously and are not living together, on the supposition that there is a special sympathy between them?

Now while I should place in the first rank those cases in which there may be fairly said to have been contagion, in the sense that Fear is contagious, or that we speak of the contagion of a good or barl example, I include under the term Double Insanity, not only :-

(1.) Cases in which A. B., being insane, affects C. D. in consequence, and infects him with the same mental disorder; but-

(2.) Cases in which C. D. becomes insane from companionship with $\mathrm{A}$. B., not in eonsequence of the direct transference of morbid ideas, but in consequence of the shock or strain arising 
out of the painful impressions produced by witnessing the attack, or by the strain of nursing a patient.

(3.) Cases in which two or more persons become insane simultaneously from the same cause.

(4.) Cases may even be included in which one lunatic infects another lunatic with his special delusions.

(5.) Twins.

The following are, briefly, the particulars of two cases I was recently requested to see, and are good illustrations of the first class.

The patients, neither of whom had an insane inheritance, and were not related, were a gentleman and his wife, the former being a partner in an extensive business in the City. The latter was an Irvingite, and the prominence given by the Church of which she was a member must not be altogether overlooked in determining the causation of the attack of mental disorder. In the next place, a gentleman, also an Irvingite, paid Mr. and Mrs. - a visit, and induced them to try some experiments with the Planchette, which were regarded as very successful and remarkable. At the same period, Mr. - I may mention, had a difficulty in making his business accounts come right, and having discovered the error, or believed he had discovered it, he attributed his success to a spirit called "Minnie." Mrs. —_ was, however, the first to be carried away by the notion of spirit influence, although the strongest-minded of the two, and, as far as I can discover, it was she who drew her husband in the same path, rather than the Planchette directly. Anyway, when I saw them, the lady was the active ruling influence, and the gentleman was the passive element, and the willing subject. I found them both in berl. The formor was excited, and poured forth a stream of words. She said that spirits were constantly speaking to her, that part of their conversation referred to stabbing, and that they were cognizant of my presence in the rom, and said many things to her about me, on the whole favourable, I am glad to say. She informed me she had been impelled to use bad words. She stated, in answer to my inquiry about the sound of the voices, that their voices were not so loud as mine, but that she liad become possessed with a sort of instinctive 
sense of bearing. She heard voices with both ears, and their loudness was not affected by closing them. When I assumed that she was a believer in modern spiritualism, she indignantly denien it, said she hated it, and wished to be rid of these voices. While we were talking, one of her children was crying downstairs, upon which she remarked that the spirits told her that some one was torturing the child. But the most interesting feature of 'Mrs. __'s auditory hallucinations was this : that she heard her own words, as she spoke to me, repeated audibly and distinctly.

As regards the visual sense, she related to me having had a vision in the night when awake.

The olfactory sense was distinctly affected. She complained of a smell of death-" like vaults, you know."

I could not clearly make out any gustatory hallucination.

General sensation was normal. 'There was no anæsthesia whatever.

Physically, her countenance was flushed, her head hot; the skin was moist and warm. The temperature in the axilla was $100^{\circ}$, the pulse 90 , and full. The tongue rather dry. The pupils were somewhat dilated, and re-acted well to light. Bowels confined three days.

I should mention that her left hand was bandaged, as she had cut it in thrusting her hand through the window in the night in order to keep the devil out. In fact her excitement was 80 great, that the governess barricaded her bedroom door, and a servant fled from the house in her night-dress, and took refuge in the nearest signal-box on the railway. Whether the signals were neglected that night $I$ have not been able to sscertain.

Having examined this patient, whose form of mental disorder may well be called that of demonomania, I passed to the other side of the bed, and pursued my enquiries into the condition of the husband, who during this time had maintained silence, although he had been much excited in the morning, the wife (I should have mentioned) having been at the same time in a sort of stupor for many hours.

On conversing with $\mathrm{Mr}$. _- I found him fairly calm, but possessed with the same delusions and hallucinations as his 
wife. He told me he heard voices ordering him to do certain things. He said he believed that they had administered strychnia to him. He assured me that a clerk in his business was a medium, and exerted an influence upon him and his wife.

It was interesting to note that, while she complained of entire sentences being immediately repeated, he stated that the latter part only of each sentence was repeated.

With regard to the visual sense, he, like his wife, saw, as he said, the red sun in the room in the middle of the night. Since his recovery he has informed me that during this attack he could see with exquisite vividness the railway and the trains pass his house, at a distance which prevented him seeing them at all clearly when he was well.

Like her, also, he suffered from hallucinations of smell, and was free from those of taste.

His physical condition does not call for remark. His pulse was 80 , his tongue moist, his temperature normal. His bowels were constipated. The pupils acted well to light.

On my advising him to go into another bedroom, he said he did not like to do so, as the gentleman who had been staying with them having occupied it, there were evil spirits remaining there.

These mental symptoms had manifested themselves for less than a week, and the malign influence of the visitor had been exerted for some days previously. The wife appears to have been the first to become affected, and, as I have already said, was the one to impress the husband with a belief in the reality of those hallucinations.

These patients remained together, notwithstanding my strong recommendation that they should be separated; yet they improved under treatment, and eventually recovered after a change to the seaside; but the husband at the present time, although attending to business, confides to me that whenever he is tired, the voices return, often addressing him in very unparliamentary language for not listening to them ; but, he adds, "there is no fear of my doing 8o, and I do not admit hearing them to any one."

It may be open to doubt whether the following is an 
instance of Folie à deux, or whether it was a mere coincidence that the symptoms of one patient resembled those of the other, but the case is interesting.

A gentleman of large means became possessed of the idea that his food was tampered with. Labouring under this suspicion of poison being placed in his food, he would secrete a piece of bread during dinner, and when he retired to his study would carefully examine it. In this way his collection of morsels of bread was often very considerable, and on one occasion when his house was broken into at night, the burglurs opened his escritoire-only to find a collection of stale bread. This gentleman moved in society, and frequently took the chair at public meetings, and very few were aware of his peculiar delusions. Among those who did know of them were the servants in the establishment, including the coachman. He was a highly-respectable and steady man, and loyal to the backbone to his master. His mind gave way without any shock or worry, and the form of mental disorder was that of suspicion of poison in his food. When called in to see him I could not fail to be struck with the resemblance between the mental symptoms of the coachman and his master, and I need hardly say that I should not have commented on it to any member of the family. But the gentleman's own daughter spontaneously made the remark: "Why he has got the same delusions as those which have affected papa." In some of the other symptoms she also detected a resemblance.

I repeat that this occurrence may have been only accidental, but at any rate $I$ think it quite possible that, while the coachman's attack of insanity was quite independent of that of his master, he, when he broke down, dwelling moodily upon his condition, he bethought him of those delusions of poison by which his master had been possessed, and began to give credence to them, and then to suspect that he himself was the object of the same malign influence.

Having observed in the last 'Report of the Isle of Allan Asylum 'the admission of a man, his wife, and their daughter on the same day, I wrote to the Superintendent, Dr. Richardson, for the particulars, and, thanks to his courtesy, I am able to give them here. 
The father, Willinm Cairn, admitted Feb. 26, 1886, was 70 years of age, a farmer, and believed himself to be pursued and persecuted by the whole House of Keys; that he was the owner of extensive property, out of which he had been kept by that House and the high bailiff. He asserted that mobs had been raised to destroy his houses and cut down his trees. He had, he said, been assaulted by the men who had robbed him, with crowbars and pickaxes; when he endeavoured to obtain redress of these grievances, he had been prevented by telegrams and ghosts.

His wife, ten years younger, asserted that her property had been sold against her will; that she had telegrams from invisible wires to say she must hang herself in consequence; and that her neighbours had put blood on the door and over the house.

The daughter of these people, admitted on the same day, was 26 years of age ; was silent and morose, with the exception of saying " first-rate " to enquiries about her health. Her mind, in fact, was too demented to allow of her entertaining the delusions of her parents. How long she had been affected is not stated, but Dr. Richardson informs me that she had returned home from service some time previously, and he is of opinion that the insane ways of her parents had much to do with inducing her present condition of mind.

As to the man and his wife, the first symptoms arose about sixteen years ago after the loss of a little farm. They began to think they were entitled to property of great value, and eight years ago they went to London to Somerset House, to establish their claim, and have, their relatives say, spend "many a bright pound" in their search after the imaginary wealth.

Last year, in France, a whole family, consisting of six persongthe father, mother, two sons, and two daughters-were simultaneously attacked with demonomania. Dr. Lapointe, who reports the circumstance, states that they were orderly people, economical, temperate, and were generally esteemed. They were, however, hypochondiacal, and possessed of mystical ideas. They gradually came to believe that they were poisoned by sorcerers; the devil was in their clothes; they constantly saw him. They desired to be freed from his presence by exorvism; they regarded themsolves as lost, and gave themselves up to many eccentric practices. At last they became dangerous, wandered about, and attacked the 
peasants, so that it became necessary to place them in an asylum. At the end of a fortnight they were discharged from the asylum, apparently recovered. During two years they resided on the farm which they cultivated: Then, suddenly, the mother gave the signal of an attack, and the same ideas were reproduced in all the members of the family. It became necessary to place them once more in an asylum. It may be added that another member of the family, a son, being from home, was by this means saved from an attack of insanity. ${ }^{1}$

Here is an instance of Folie à quatre, reported by an Italian physician.

A woman, aged 47, was the daughter of a man who, having been a foundling, devoted part of his life to trying to discover who were his parents. In consequence of constantly hearing her father speak of his mysterious origin, sho began to think he must be descended from some one of noble birth, whose fortune she would some day inherit. This idea, which became an insane delusion, she communicated to her mother, and also a lady in whose service she was as femme de chambre. This lady systematised the delusion still further, and believed that the rich ancestor of her prolégé was a general in the First Empire, and that he had bequeathed a million francs to the hospital at Milan. Of course all the pains she was at, all her negotiations, ended in nothing, and all her statements werè disputed.

Strange to say, the principal actor in this series not only married, but succeeded in conveying the delusion to her husband. Thus four persons were all inoculated with the same ideas, and, as might be expected, these were followed by hallucinations and suspicions of poison. In vain were they separated; they remain insane at the present time. ${ }^{2}$

When two lovers agree to commit suicide together, we may perhaps be in doubt whether they are, strictly speaking, insane. Still the fact serves clearly to illustrate the influence exerter by one mind over another in regard to a morbid train of ideas, and ideas of sufficient force and intensity to occusion desperate deeds. The following cases of simultaneous suicide, not of lovers, mas be fairly regarded as illustrations of Folie à deux:

In May last, two young ladies of Munich, the Baronesses Anna and Louisa Guttenburg, aged respectively 26 and 23, committed

1 'Aunales Médico-psychologiques,' November, 1886.

2 "A relivio Italiano per le malatie nervose," \&c., xxi. fasc. 5 and 6. 
suicide by drowning themselves in the Stannberg Lake, on the identical spot where the King of Bavaria was found dead eleven months before. It is stated that they had held many melancholy conversations on the tragical fale of the King, and repeatedly went to the Lake in order to throw flowers into his watery grave. At last they gave way to the impulse of following the King's example, and taking a boat to the spot, which is close to the shore, they dropped silently into the water. Next moruing, when the missing boat roused suspicions, a search was made, and they were found in the soft clay, firmly clasped in each other's arms. They were both pretty, highly cultivated, and rich. ${ }^{3}$

I think that a tragedy which occurred recently in Vienna may be properly placed under this division.

A lady lost her husband some years ago. She then begged an elder unmarried sister to live with her. In the cuurse of time, the grief of the widow turned her head, and she became quite insane aud was placed in an asylum. Up to this point of the history we have not an example of Folie à deux. It was the grief of the widow upset the sister's mind. Whether they belonged to an insane family is not stated. But now comes the portion of the story which bears on the subject of my paper. Last Christmas the insane sister was discharged from the asylum, recovered. The result was, that after her réturn to her widowed sister she not only relapsed, but infected her sister, and at length they resolved to. commit suicide. They took $a$ cab and drove to the foot of the Kohlenberg, where it rises abruptly from the Danube. Having dismissed the cab, they were seen sauntering along the bank of the river. Shortly after, a railway guard saw a female figure floating on the water. Having taken a boat, he succeeded in getting the body out. He then discovered that a second woman was fastened with cords to the back of the first. The woman at the top was the insane sister, and was restored to consciousness after a short time, and recovered. The other sister-the widowwas dead. While this was being ascurtained, the sister who had been saved ran to the river and threw herself in again, but $u$ as again rescued. She was sent hack to the asylum, from which she had probably been too soon discharged.

Having given striking examples of the first class of cases in which contagious sympathy exerts a great influence, $\mathbf{l}$ proceed to give an illustration of the second class of cases, those, 
namely, in which an insane patient caused the attack of insanity in another from shock, or strain.

I was consulted about a married lady in consequence of her having become mentally deranged, the form of the disorder being melancholia with suicidal tendencies. The birth of a child-the first-and a good deal of domestic anxiety appeared to be the causes of the attack.

A sister of this lady was summoned by a telegraph to join her. She had attended her in her confinement, was not in strong health, and was somewhat unnerved, as was but natural, by being sent for to her sister on account of illness. She was by nature quiet and undemonstratire, and did not betray any undue emotion; so that the patient's husband had certainly no idea of there being anything the matter with ber when she came to see her sister. She arrived on a Tuesday; she was alone with her till the Friday. Then a mutual friend went over by accident to see them, and Miss —_, the visitor, shortly said, "I must go home at once, or I shall go mad." A medical friend attributes this to the shock of finding her sister insane.

She left the same day, travelling home alone. The mutual friend, finding her quite as insane as the patient, was very uneasy at her making the joutney by herself. From the time she reached home she was in a state of extreme mental depression, becoming at last much worse than her sister. About two months later she made a serious attempt on her life, by cutting her throat with a razor. She was then removed to an asylum, and for several months was not expected to live. She was ill for at least a year, rarely uttering a word and profoundly depressed. Recovery followed, and she has remained well.

The sister who was first attacked, and was my patient, never passed into so bad a state, and it was not necessary to place her in an asylum. She recovered perfectly.

In regard to these cases (those in which visiting, nursing, or taking charge of an insane patient induces a prejudicial mental effect) it is of course difficult, if not impossible, to decide how much is due to imitation and sympathy, and how much to the mere strain from constant attention to the patient. It is remarkable that attendants in asylums do not 
break down mentally oftener than they do. Indeed, seeing that some attendants are bound to become insane whether attendants or not, I think the fact that attacks of insanity in this service do not attract special notice is a proof that the contagion of insanity is somewhat rare.

Without pretending to accurately determine, in the following case, how much was due to mere companionship and how much to the responsibility of having charge of the patient, I think it is worth mentioning in this connection.

Miss —_, a young lady acting as constant companion to a patient of mine in lodgings for a period of some months, became the subject of mental symptoms herself. The patient had delusions, but her companion became simply depressed and hypochondriacal, without any delusions. She went into a medical man's house, and becoming worse, desired to be admitted into an asylum. I do not think there was any transference, in this case, of insane ideas from the patient to her companion, but that the care of the case was the real cause in a lady who was predisposed.

In a very sad case about which I have been recently consulted, I have no doubt of the influence exerted by an attack of insanity in a lady upon her sister who was with her at the time. The latter felt the shock of the event deeply, called in question the necessity of placing her sister in an asylum, and became alienated from other members of the family. She could not sleep, and was unable to pursue her avocations. A near relative had previously been insane, but there was no evidence of heredity.

My third class comprises cases in which two or more persons become insane simultaneously from the same cause.

The most familiar illustration of this class is the effect produced by the Revivalist. The immediate excitement, and even the hysterical convulsions induced, are conditions which cannot be ignored in their bearing upon the influence which may be exerted by that rapid spread of sympathetic feeling which we recognise as epidemic in our own days, as well as in the Middle Ages, although they may pass off without constituting actual insanity. But the effects are sometimes, unfortunately, permanent, and constitute then striking examples

VOI. $x$.

$2 \mathrm{E}$ 
of Folie à deua or a larger number. I shall not occupy space in bringing forward cases falling under this category, but proceed to the

Fourth class of cases, those namely, in which one insane patient infects another lunatic with his or her delusions. That this is a much rarer event than one might have expected will be admitted by any one who has endeavoured to collect examples. Laségue regarded this occurrence as very rare. However, such cases do from time to time occur, and I will briefly cite one or rather two I have seen in Bethlem Hospital, which were under Dr: Savage's care.

Mrs. S. was admitted into the hospital on March last, labouring under delusions, the most prominent being that she was infected with syphilis, which, by her touch, had infected all others, far and near, even her most gracious Majesty. No evidence of syphilis could be obtained.

When in the hospital she was depressed, and talked freely about her delusion. She was frequently with Mrs. A., a patient in the same ward, and after awhile it was found that the latter was possessed of the same delusion in regard to herself. On the 18th of June last I specially questioned her on this point, and found that she fully believed herself to be labouring under syphilis. She interpreted some tonsillitis, which she had, to be a syphilitic sore throat, and referred to other symptoms also as being due to the same cause. I could not make out that she thought the other patient had infected her. It appeared that she had simply adopted her delusion. I may add that, on her admission, she was labouring under great mental depression and intense suicidal tendency, and had auditory hallucinations.

Although cases of this kind undoubtedly occur occasionally, the general disposition of the insane is to hold tenaciously to their oun delusions, and to smile at the delusions of their comrades in disease.

The fifth and last class has reference to the insanity of twins.

I saw an example in the York Asylum, some years ago, of twins in a state of acute mania at the same time, but I cannot recall the particulars. There have been some marked cases at Bethlem Hospital in which a very similar course has been run 
by twins. It really seemed as if there was a sort of sympathy between them, or perhaps it would be more correct to say, that two constitutions having originated and been built up at the same time, and under precisely the same circumstances, they were so nearly identical that the exciting causes of insanity produced, when operating upon them, the same result. The coincidence was curious, that such causes should happen to come into operation at the same time.

There is now a man in Bethlem in an adranced condition of general paralysis, whose twin brother has been under Dr. Clouston, at the Moningside Asylum, as a general paralytic. There was not a long period between the invasion of the attacks in each. Dr. Clouston's patient is dead, Dr. Savage's is in the third stage of the disease.

Some time ago there were twin sisters in Bethlem, whose histories ran a singularly parallel course, although not together.

There were admitted in Mareh, 1880, into the Southern Counties Asylum; Dumfries, twin sisters, Eliza and Isabella Scott. I have obtained from Dr. Rntherford copies of the certificates. Unfortunately the other particulars are extremely scant. They closely resembled one another; were 23 years of age, single, and domestic servants. No other members of the family had been insane. The attack dated in both from the same day-ten weeks before admission. Both are stated to have had a previous attack of insanity, and also at the same period, viz. when they were 19.

The cause was not known.

They were suicidal, and dangerous to others. Eliza was suspicious of being poisoned, and had delusions about her friends. Isabella refused her food. Both were in a state of great excitement and incoherence. Isabella alternated between frenzy and depression.

Eliza's excitement passed away in about a week, and she was discharged, recovered, in rather less than two months.

Isabella did not recover so quickly, but she was discharged, recovered, in about nine months. She subsequently married; her recovery was apparently complete.

\footnotetext{
1 The patient has died since this was written.
} 
To these cases I would add a few observations. Under whatever head the cases may fall, it is important in studying them to have in mind these among other questions :-

(a) Are the patients members of the same family ?

(b) Is there an insane inheritance, or, if not, is the patient, who appears to be the passive subject or parasite, distinctly neurotic? The question of predisposition is, for obvious reasons, highly important.

(c) How soon after A. and B. met did B. manifest mental disorder?

(d) How long did they continue to associate?

(e) To what extent did the passive subject develop symptoms identical with those of the active agent?

$(f$,$) Were they separated, and if so, what was the after-$ history of the patients, more especially that of the passive subject?

Conclusions:-

(1.) I think that experience shows, that the influence of the insane upon the sane is very exceptional, except under certain conditions, which can be laid down with tolerable accuracy.

(2.) As an almost universal rule, those who become insane in consequence of association with the insane, are neurotic or somewhat feeble-minded.

(3.) More women become affected than men.

(4.) It is more likely that an insane person able to pass muster, as being in the possession of his intellect, should influence another in the direction of his delusions than if he is outrageously insane. There must be some method in his madness.

(5.) The most common form which cases of communicated mental disorder assume is that of delusion, and especially delusion of persecution, or of being entitled to property of which they are defrauded by their enemies. Acute mania, profound melancholia and dementia are not likely to communicate themselves. If they exert a prejudicial effect, it is by the distress these conditions cause in the minds of near relatives.

(6.) A young person is more likely to adopt the delusions of an older person than vice versâ, especially if the latter be a relative with whom they hare grown up from infancy. 
(7.) It simplifies the comprehension of this affection, to start from the acknowledged influence which a sane person may exert upon another sane person. It is not a long road from this to the acceptance of a plausible delusion, impressed upon the hearer with all the force of conviction and the vividness of a vital truth.

(8.) It is not easy to determine to what extent the person who is the second to become insane, affects in his turn the mental condition of the primary agent. My own cases do not clearly point to this action, but there have been instances in which this has occurred; the result being that the first lunatic has modified his delusions in some measure, and the copartnership, so to speak, in mental disorder, presents a more plausible aspect of the original delusion.

(9.) Is it possible that those who are frequently with the insane become more irritable than they otherwise would have been, without being actually insane? This has been asserted by a French physician, but I am not prepared to support it.

I would say, in conclusion, that the subject I have discussed, is one of practical importance as well as curious interest.

We ought to be alive to the considerable danger of one member of a family who becomes insane endangering the mental health of another member of the family. I should discourage a sister nursing for long an insane sister, though I have a patient at present who is to a large extent nursed by her three sisters, and this in a family where a brother has been under my care, and a sister and the mother have been insane.

Their devotion is, however, so great, that they do not like to leave their sister in the hands of strangers.

Again, I think that we should discourage susceptible young women, and especially hysterical ones, from associating with persons having delusions, or even entertaining wild eccentric notions short of insane delusions.

Lastly, when such cases fall under our treatment, there can be no difference of opinion as to the importance of separating promptly the patients who are affected, and of changing the scene completely. The passive agent-the parasitic growth-will probably gradually recover in a fresh and more wholesome environment. 